\title{
Chapter 9 \\ Regulation of High-Temperature Stress Response by Small RNAs
}

\author{
Henrik Mihály Szaker, Péter Gyula, György Szittya and Tibor Csorba
}

\begin{abstract}
Temperature extremes constitute one of the most common environmental stresses that adversely affect the growth and development of plants. Transcriptional regulation of temperature stress responses, particularly involving protein-coding gene networks, has been intensively studied in recent years. High-throughput sequencing technologies enabled the detection of a great number of small RNAs that have been found to change during and following temperature stress. The precise molecular action of some of these has been elucidated in detail. In the present chapter, we summarize the current understanding of small RNA-mediated modulation of hightemperature stress-regulatory pathways including basal stress responses, acclimation, and thermo-memory. We gather evidence that suggests that small RNA network changes, involving multiple upregulated and downregulated small RNAs, balance the trade-off between growth/development and stress responses, in order to ensure successful adaptation. We highlight specific characteristics of small RNA-based temperature stress regulation in crop plants. Finally, we explore the perspectives of the use of small RNAs in breeding to improve stress tolerance, which may be relevant for agriculture in the near future.
\end{abstract}

Keywords Plants $\cdot$ Heat stress $\cdot$ RNA silencing $\cdot$ Thermomemory $\cdot$ Adaptation

\subsection{Introduction}

Temperature is a primary environmental factor that is continuously monitored by living organisms to adjust their growth and reproduction accordingly. Due to climate change, the global temperature is constantly increasing. Besides this, the frequency and amplitude of extreme temperature events are also elevated. Extreme temperatures exceeding the optimal range of a given organism have an adverse impact on almost every aspect of life including growth and reproduction. The extreme heat exposure damages lipid membranes, proteins, and nucleic acids, etc. Being sessile organisms,

H. M. Szaker · P. Gyula · G. Szittya · T. Csorba $(\bowtie)$

National Agricultural Research and Innovation Center, Agricultural Biotechnology Institute (NARIC-ABC), Szent-Györgyi A. 4, Gödöllő 2100, Hungary

e-mail: csorba.tibor@abc.naik.hu 
plants are especially exposed to extreme temperature fluctuations and heat stress (Luria et al. 2019; Mazzeo et al. 2018; Mittler et al. 2012; Ohama et al. 2017; Scharf et al. 2012). To mitigate the negative effects, heat stress response (HSR) pathways are initiated. HSR is a multilayered complex set of physiological and phenological alterations that help plants to cope with the extreme temperatures and sudden temperature changes and enables survival and reproduction (Mittler et al. 2012; Ohama et al. 2017; Scharf et al. 2012). HSR acts on epigenetic, transcriptional and post-transcriptional levels (Ohama et al. 2017).

\subsection{Regulation of HSR}

Plant heat stress response is initiated by a number of signaling mechanisms. One central role of heat stress signaling is the activation of Heat Stress Factors (HSFs). HSFs are pioneer transcription factors (TFs) that recognize and bind to tandem inverted repeats of nGAAn consensus sequence within the target gene loci to activate transcription (Maruyama et al. 2017). HSF family comprises multiple members (for example Arabidopsis thaliana has 21, Brassica napus 64, soybean 52, maize 30 members) (Scharf et al. 2012; Zhu et al. 2017). HSF members show high functional diversification and partial genetic redundancy. HSFs might be induced during other stresses or combined stress conditions as well. The master regulators of HSR are the Heat Stress Transcription factors HSFA1 family proteins (in A. thaliana HSFA1A, HSFA1B, and HSFA1D) (Liu and Charng 2013; Liu et al. 2011; Ohama et al. 2017; Yoshida et al. 2011). In the absence of these factors, induction of a large number of downstream HS-inducible genes is absent, and plants become HSsensitive. Temperature-sensitivity of plants becomes apparent already at high ambient temperatures in hsfal-mutant plants, suggesting that the HSF-mediated stress pathways are initiated at these temperatures (Cortijo et al. 2017). HSFA2 is a direct target of HSFA1s and is a major enhancer of thermotolerance. HSFA1 and HSFA2 proteins form a heteromultimer TF complex (superactivator complex) and strongly induce expression of downstream HSFs, transcription factors, heat shock proteins (HSPs), non-chaperone proteins or non-coding RNAs (Chan-Schaminet et al. 2009; Scharf et al. 1998, 2012). If plants encounter mild temperature stress they become acclimated. This, so-called acquired thermotolerance, allows plants to survive later stronger heat stress exposures (Lin et al. 2014; Liu and Charng 2012). Acquired thermotolerance may be actively maintained for several days post-stress through a process called heat stress memory (Brzezinka et al. 2016; Charng et al. 2007; Lamke et al. 2016; Liu et al. 2018; Stief et al. 2014). Transcriptional memory allows a faster or stronger stress response to be initiated when the same stress is re-encountered. HSFA2 is a central component of thermomemory. Transient binding of HSFA2 induces deposition of Histone 3 lysine 4 dimethylation and trimethylation (H3K4me2, H3K4me3) at memory loci (Lamke et al. 2016). These histone modifications persist after active transcription was subsided, marking them as recently transcriptionally active. Upon recurring heat stress, transcription of these memory 
loci is hyperinduced, and thus enables a quicker and more efficient HSR. Besides HSFA2, a growing number of stress memory factors have been discovered (Brzezinka et al. 2018; Charng et al. 2006; Lin et al. 2014; Liu et al. 2018; Meiri and Breiman 2009). Thermomemory was shown to be transmitted transgenerationally (Liu et al. 2019). Micro RNAs (miRNA) and small interfering RNAs (siRNA) are intimately involved in high-temperature stress response and thermomemory.

\subsection{Abiotic Stresses Alter sRNAs' Level}

The central molecules of RNA silencing pathways are short non-coding regulatory RNAs (small RNAs, sRNA), with the size of 21-24 nucleotides (Axtell 2013; Borges and Martienssen 2015; Rogers and Chen 2013; Vaucheret 2006). There are several classes of sRNAs including miRNA and small interfering RNAs (trans-acting siRNAs or ta-siRNAs; heterochromatic siRNAs or het-siRNA, repeat-associated siRNAs or ra-siRNA, etc.). miRNAs and siRNAs differ in their biogenesis. miRNAs are encoded on distinct genomic loci; their precursors (pri-miRNA) are transcribed by RNA Polymerase II, capped, and polyadenylated. In A. thaliana, DICER-LIKE 1 (DCL1), together with SERRATE (SE) and HYPONASTIC LEAVES 1 (HYL1) forms the Microprocessor complex. Microprocessor complex processes pri-miRNAs in two subsequent steps to generate pre-miRNA then mature miRNAs. miRNAs are mostly 21-nt long; they are loaded into RNA-induced Silencing Complex (RISC) effector protein ARGONAUTE (AGO1 in A. thaliana) and guide sequence-specifically the cleavage or inhibit translation of complementary target mRNAs through a process called Post-Transcriptional Gene Silencing (PTGS) or RNA silencing. 22-nt-long (or in special cases, 21-nt-long) miRNAs not only cleave their targets but also trigger the biogenesis of secondary siRNAs. Secondary siRNA biogenesis requires the activity of DCLs, AGOs and RNA-DEPENDENT RNA POLYMERASES (RDRs). In A. thaliana, DCL4, AGO1 or AGO7, and RDR6 are the key enzymes involved in secondary siRNA biogenesis (Dalmay et al. 2000; Martinez de Alba et al. 2013). The secondary siRNA further represses target RNAs in trans (at PTGS level), therefore, are called trans-acting siRNAs. miRNAs and ta-siRNAs are involved in almost every aspect of plant growth and development.

The 24-nt-long siRNAs (het-siRNA, ra-siRNA) originate from long doublestranded RNA molecules and serve to silence specific regions of the genome through guiding DNA methylation (RNA-directed DNA methylation, RdDM) and subsequent histone modifications (Borges and Martienssen 2015). This affects gene expression at the transcriptional level; therefore, the process is called Transcriptional Gene Silencing (TGS). During TGS, stable repression of transcription is established at transposons, chromosomal repeats, transgenic inserts but also may occur at certain protein-coding genes. The main function of TGS is the preservation of genome stability and epigenetic regulation of certain genes.

To date, thousands of sRNA have been identified through bioinformatic predictions, cloning and deep sequencing, or hybridization methods both from model plants 
and numerous crops (Baksa et al. 2015; Barciszewska-Pacak et al. 2015; Beckers et al. 2017; Gyula et al. 2018; Kruszka et al. 2014; Liu et al. 2017; May et al. 2013; Mohorianu et al. 2013; Zhou et al. 2016).

Besides their role in growth, development and genome stability, sRNAs are also important components of stress responses. Environmental alteration of sRNAs was observed in a variety of species like A. thaliana, Brassica rapa, Populus euphratica, Triticum aestivum, Oryza sativa, etc. (Barciszewska-Pacak et al. 2015; Chen et al. 2012; Kumar et al. 2015; Mangrauthia et al. 2017; Sunkar and Zhu 2004; Xin et al. 2011; Yu et al. 2012). Different environmental conditions including heat, drought, salt, oxidative stress, hypoxia, cold, nutrient deprivation, UV-B, strong light, etc. caused severe alteration of sRNA levels or biosynthesis of novel sRNAs (see Table 9.1). Stress-responsiveness suggests regulatory roles during stress or recovery period. This is supported also by the differences between sRNAs' stress-response observed between stress-sensitive and -tolerant varieties or cultivars (Liu et al. 2017; Mangrauthia et al. 2017).

The fact that stress-induced changes have similar trends, occur in multiple species and correlate with the stress-sensitivity, points to a conserved mechanism involving sRNAs as active players. However, some sRNAs' stress response was found to be very specific. For example, miR159, miR160, miR164, miR166, miR319 or miR398 were oppositely regulated in different species (Kumar et al. 2015; Liu et al. 2017; Xin et al. 2010): miR156 family members are induced in response to HS in A. thaliana, Brassica rapa, and wheat (Stief et al. 2014; Xin et al. 2010; Yu et al. 2012), but repressed in cassava, or rice (Ballen-Taborda et al. 2013; Liu et al. 2017); miR164 was upregulated and miR164-target NASCENT POLYPEPTIDE-ASSOCIATED COMPLEX1 (NAC1) was suppressed in Arabidopsis (May et al. 2013); oppositely to this, taemiR164 was downregulated and its target HSP17 upregulated in wheat (Kumar et al. 2015); miR164, miR160, miR319, and miR398 were upregulated in Arabidopsis but downregulated in wheat (Kumar et al. 2015). Some miRNAs possess tissuespecific changes characteristic to roots, leaves or flowers (Gyula et al. 2018; Liu et al. 2017; Mangrauthia et al. 2017). In specific cases, novel sRNA-target interactions have evolved from conserved miRNA and mRNA target components: for example, in sunflower, the HaWRKY6 transcription factor recently evolved to be the target of the highly conserved miR396 (Giacomelli et al. 2012). These findings warn that sRNA-based stress response regulation is complex. Detailed studying of unique sRNA-target pairs and characterization of their putative roles during HSR response in every specific case is required before generalization is made about their role in non-model plants.

A handful of sRNA::target pairs have been studied in detail. Accumulating evidence shows that sRNA-mediated regulation plays essential roles in plant responses to abiotic stresses, including high-temperature stress response (Cui et al. 2014; Guan et al. 2013; He et al. 2018; Ma et al. 2015; Stief et al. 2014) (see Table 9.1). sRNAs were shown to be required for adaptation to the mild elevation in ambient temperatures, some sRNAs are involved in the establishment of acute stress response, acquired thermo-tolerance or thermomemory in response to heat, while others indirectly alter development in the post-stress period. Importantly, changes in sRNA 


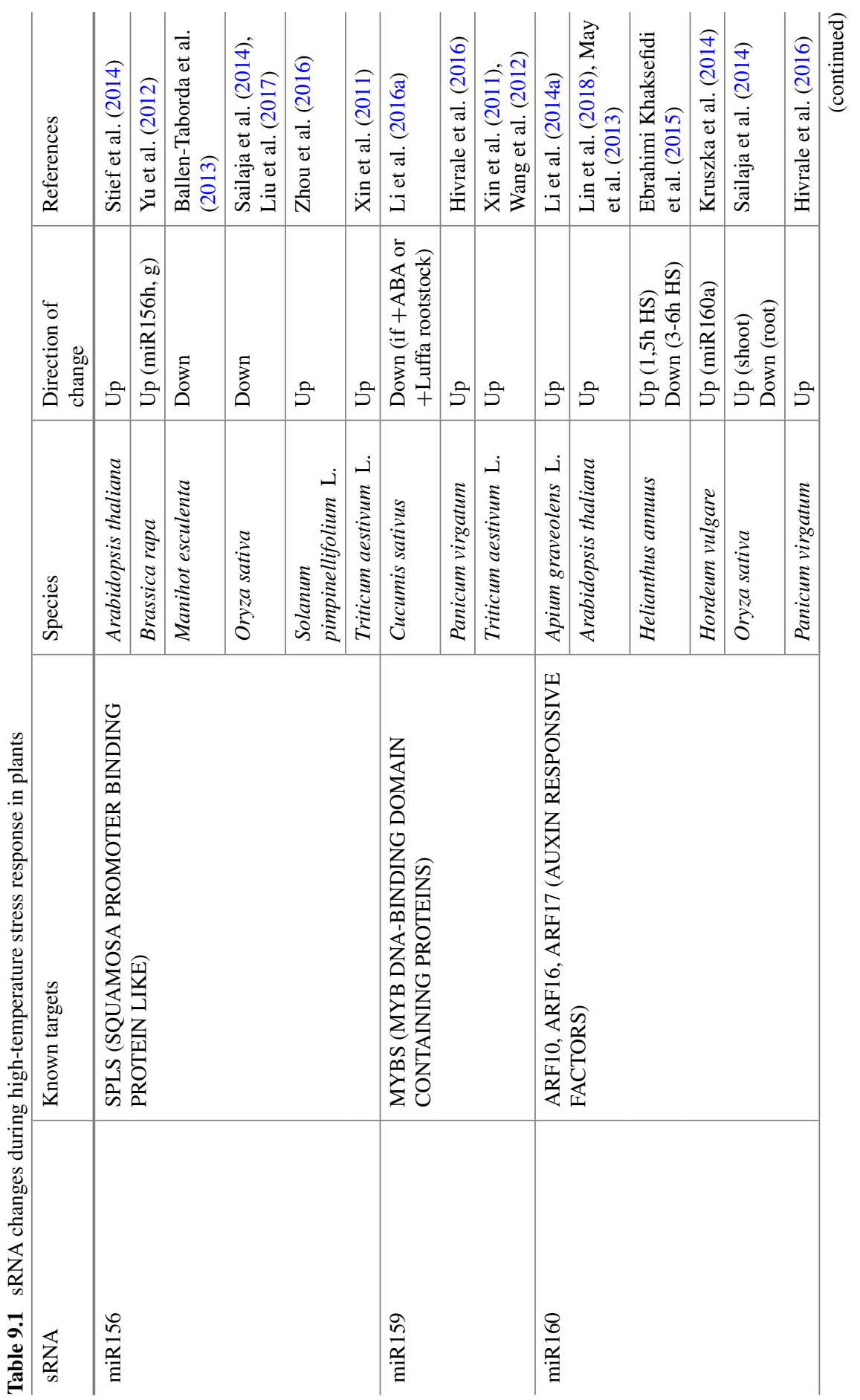









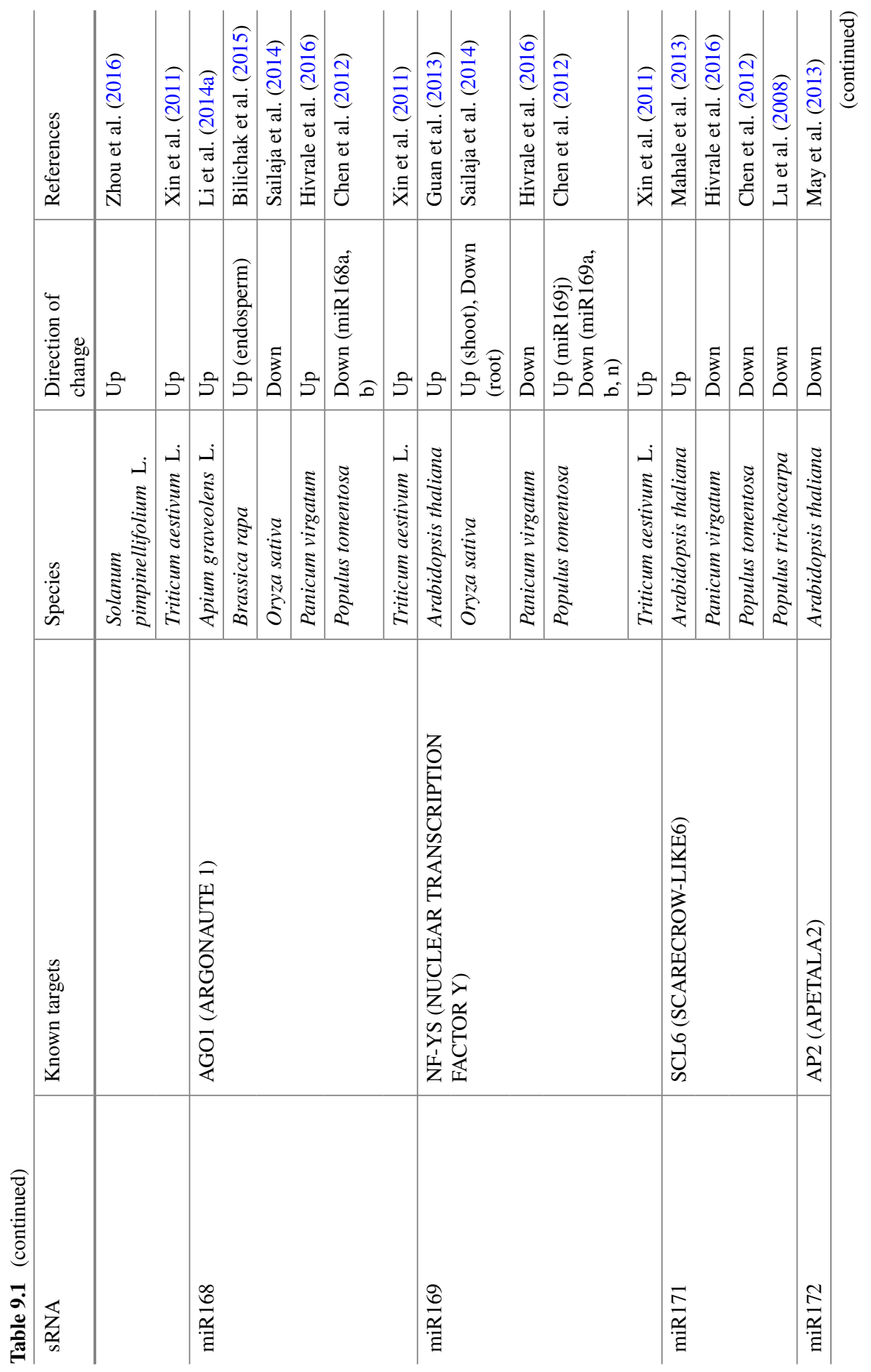




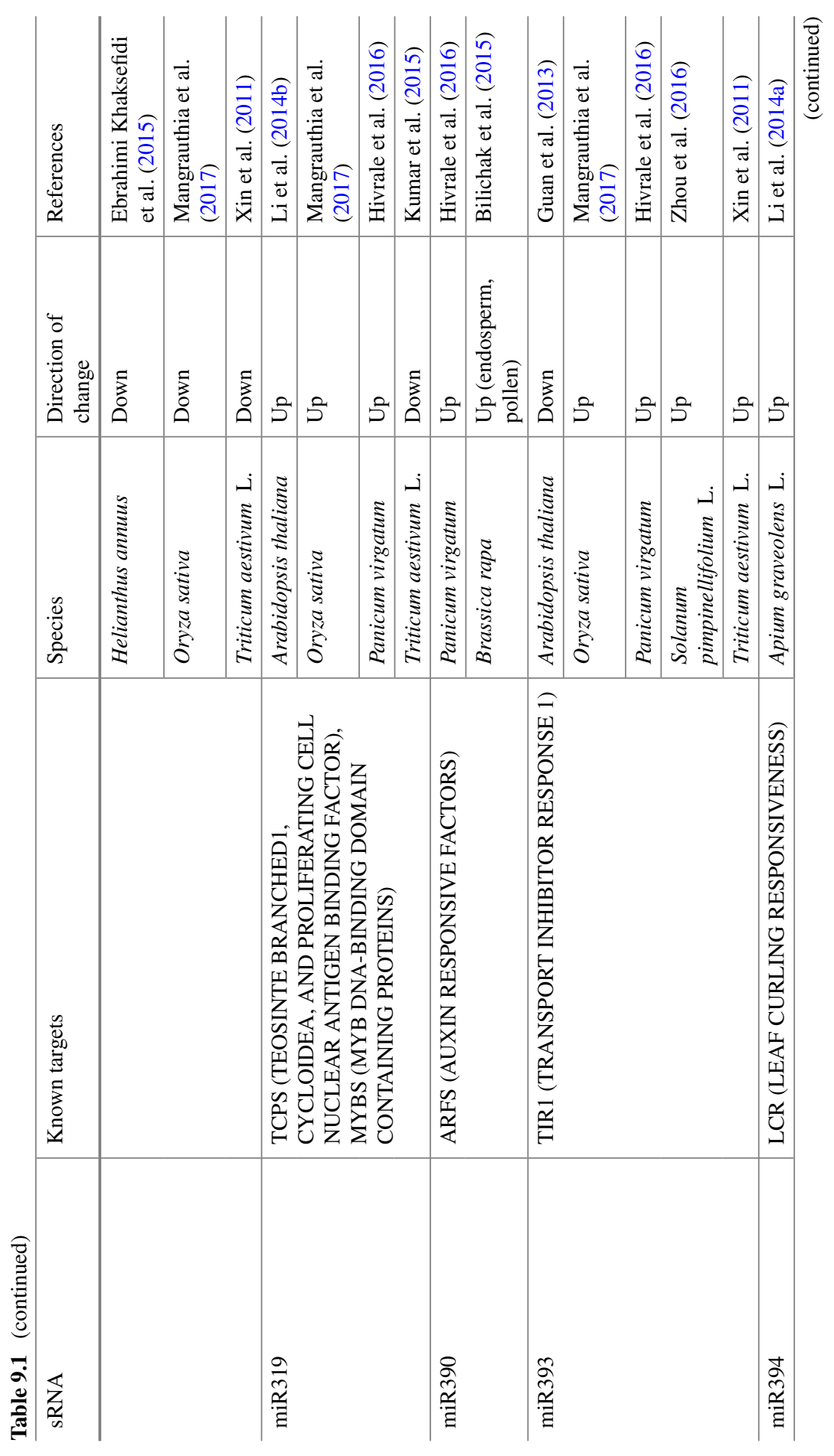




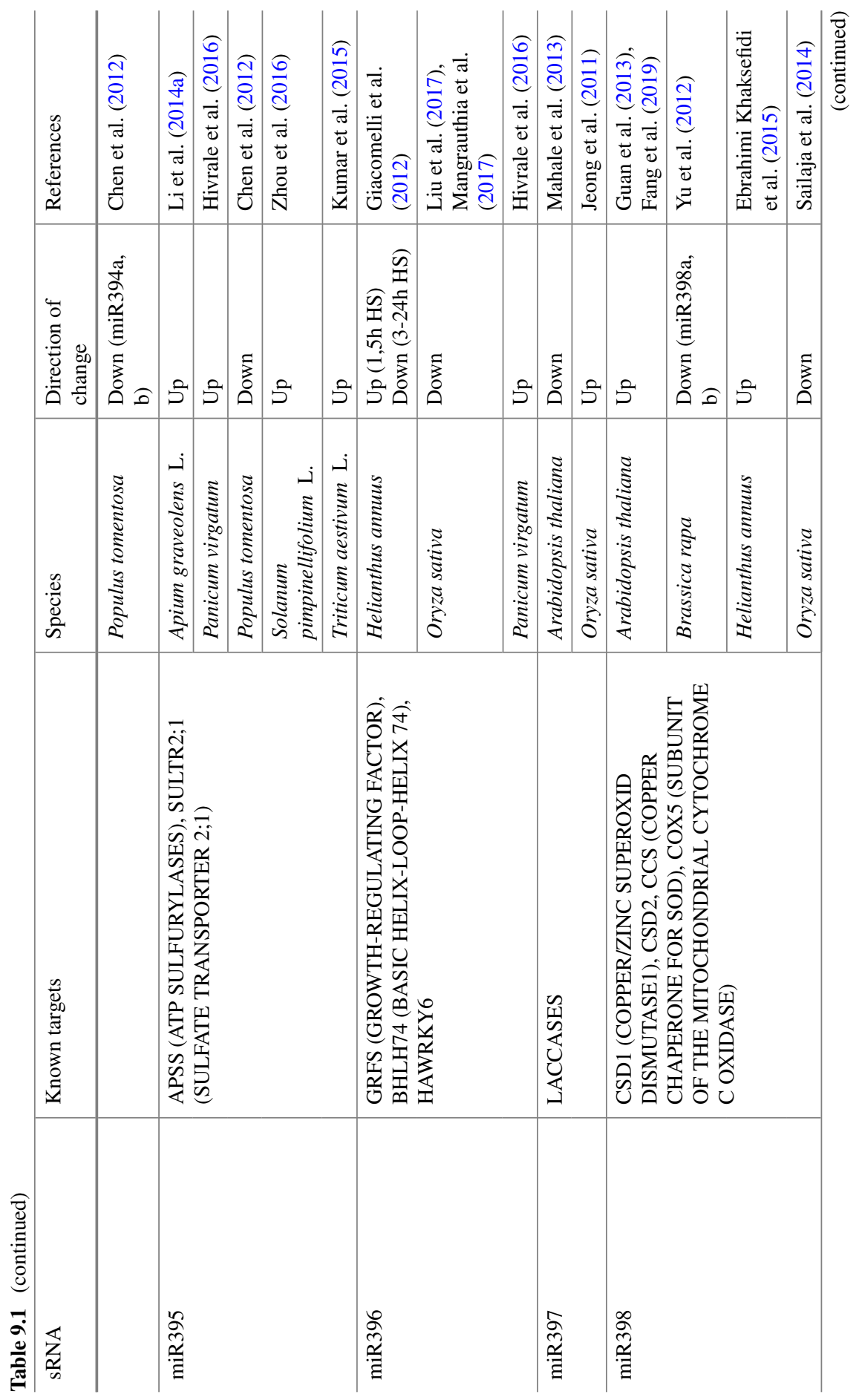




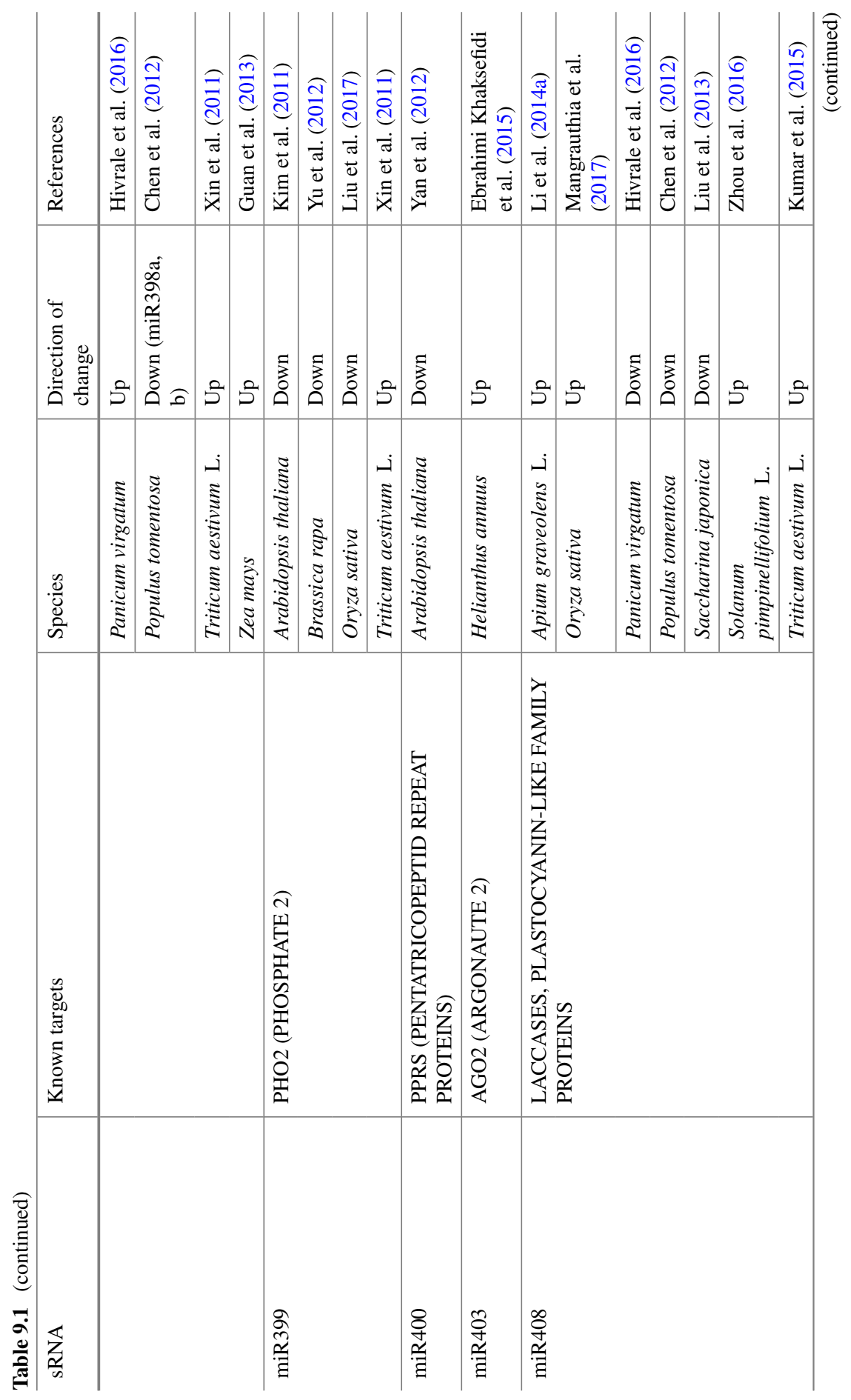




\begin{tabular}{|c|c|c|c|c|c|c|c|c|c|c|c|c|c|c|c|c|}
\hline 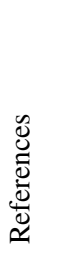 & 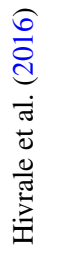 & 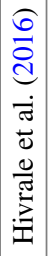 & 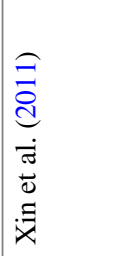 & 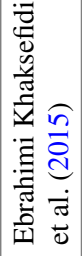 & 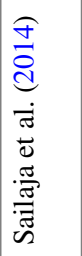 & 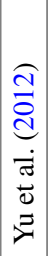 & 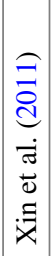 & 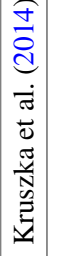 & 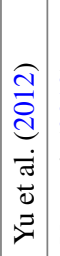 & 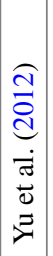 & 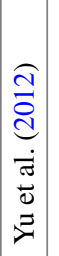 & 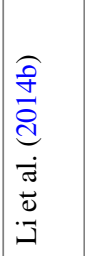 &  & 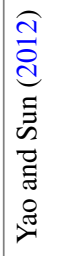 & 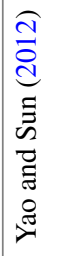 & 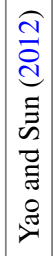 \\
\hline 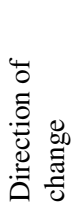 & s. & s' & s & $s$ & 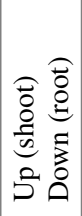 & 芌 & $s^{2}$ & 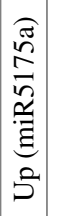 & م & 㿣 & $s^{2}$ & $s^{2}$ & 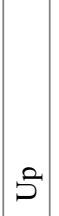 & ڤี & ڤ̊ & 今ే \\
\hline $\begin{array}{l}\frac{0}{0} \\
\frac{0}{0} \\
\text { n. }\end{array}$ & 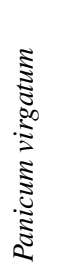 & 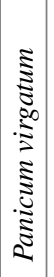 &  & 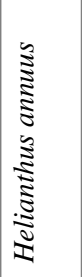 & 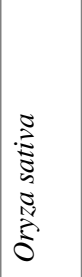 & 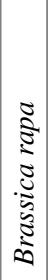 & 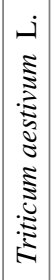 & 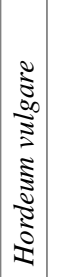 & 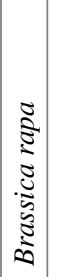 & 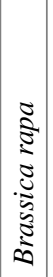 &  & 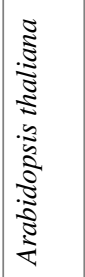 & 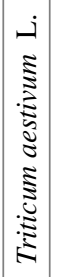 & 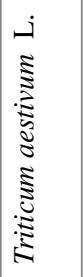 & 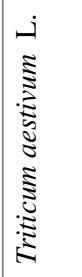 &  \\
\hline 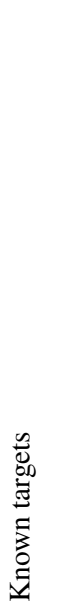 & 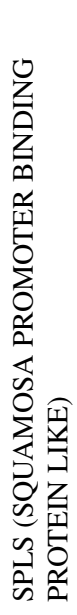 & 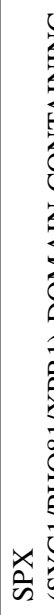 & 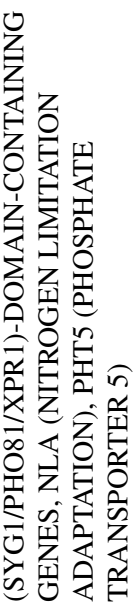 & 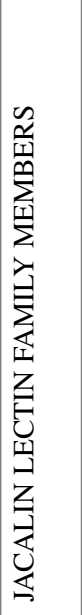 & 1 & 1 & 1 & 1 & 1 & 1 & 1 & 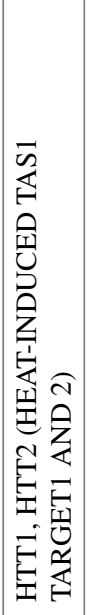 & 1 & I & 1 & 1 \\
\hline 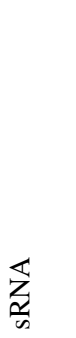 & 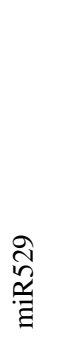 & 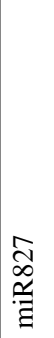 & & 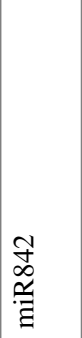 & $\begin{array}{l}\infty \\
\frac{\infty}{\not{a}} \\
\frac{\alpha}{\exists}\end{array}$ & $\begin{array}{l}\dot{0} \\
\infty \\
\infty \\
\infty \\
\underline{a} \\
\vec{g}\end{array}$ & 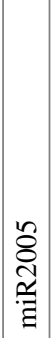 & $\left|\begin{array}{l}n \\
\frac{n}{n} \\
\frac{n}{a} \\
\Xi\end{array}\right|$ & $\begin{array}{l} \pm \\
\hat{n} \\
\frac{v}{a} \\
\Xi\end{array}$ & $\begin{array}{l}0 \\
\hat{\hbar} \\
\frac{\hat{n}}{a} \\
a\end{array}$ & $\begin{array}{l}0 \\
\tilde{n} \\
\hat{n} \\
\frac{f}{a} \\
\Xi\end{array}$ & 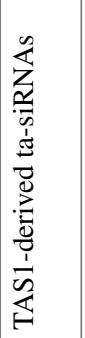 & 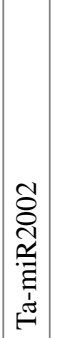 & 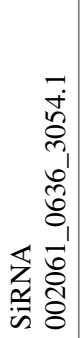 & 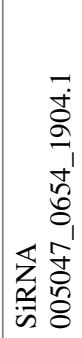 & 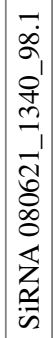 \\
\hline
\end{tabular}




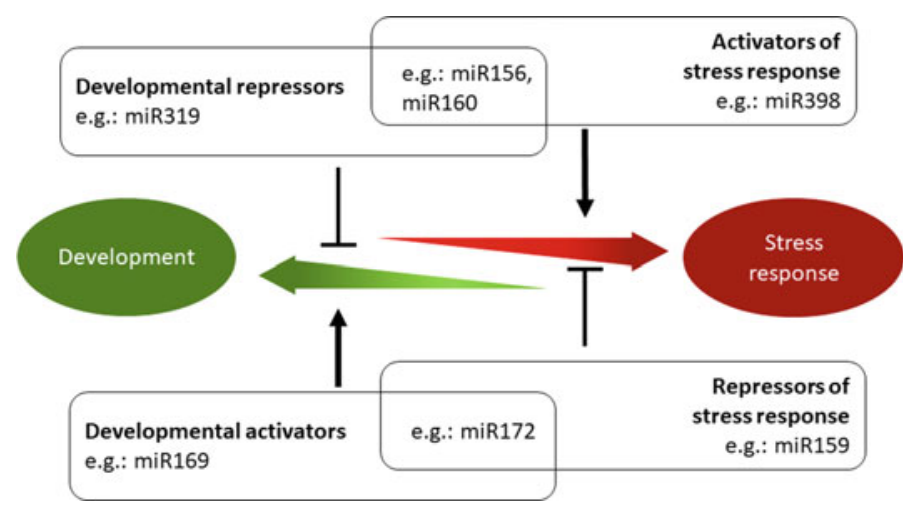

Fig. 9.1 Small RNAs act in a complex network to regulate the balance between developmental pathways and stress responses. Examples are given for each category (for activity of specific sRNAs, please see Table 9.1)

or/and target act in a complex, interconnected network that fine-tunes the balance between growth and stress response (Fig. 9.1).

\section{4 sRNAs' Involvement in the Ambient Temperature Response}

Plants substantially alter their developmental program upon changes in the ambient temperature (Quint et al. 2016; Wigge 2013). It was shown recently that changes in ambient temperature affect the steady-state levels of only a small fraction of the total sRNA loci (0.6\%) in A. thaliana (Gyula et al. 2018). One of these temperatureresponsive loci can add an extra regulatory layer to the auxin-dependent thermomorphogenesis by regulating epigenetically the expression of the auxin synthesis gene $Y U C C A 2$ ( $Y U C 2$ ). This finding also suggests that the temperature-dependency of these loci is not conferred by some common siRNA biogenesis components (i.e. PolIV/V, RDR2, DCL3) (Borges and Martienssen 2015), but some other, unknown trans factors.

Several Arabidopsis miRNAs were identified in microarray and northern blot experiments to be differentially expressed (miR156, miR163, miR169, miR172, miR398, and miR399) in response to ambient temperature changes (Lee et al. 2010). The gradient of miR156 and miR172 regulates the juvenile to adult phase transition and adult to reproductive phase transitions. miR156 is highly expressed during the juvenile stage and gradually decreasing its level as the plant ages (Poethig 2009). Targets of miR156 are the SQUAMOSA PROMOTER BINDING-LIKE (SPL) transcription factors. SPLs regulate a number of genes involved in floral time transition (Srikanth and Schmid 2011; Wang et al. 2009). Overexpression of miR156 in Arabidopsis causes altered vegetative phase transition and delayed flowering (Xing et al. 
2013; Yu et al. 2010). The level of miR156 is high at low ambient temperatures $\left(16^{\circ} \mathrm{C}\right)$ and therefore could delay juvenile to adult phase transition or floral transition. The thermodynamic properties of mir156 precursor stem-loop structure can affect the cleavage efficiency of the mature miRNA/miRNA* duplex. Structural analysis studies showed that certain positions in the mir156a precursor sequence can particularly affect the cleavage efficiency, and in turn, the flowering time at different ambient temperatures $\left(16^{\circ} \mathrm{C}\right.$ vs. $\left.23^{\circ} \mathrm{C}\right)(\mathrm{Kim}$ et al. 2016). Therefore, the mir156 precursors can serve as a temperature sensor. Furthermore, warm temperature $\left(23^{\circ} \mathrm{C}\right)$ enhances the expression of miR172, which plays the opposite role to miR156. Overexpression of miR172 causes early flowering by down-regulating the AP2-domain transcription factors TARGET OF EAT1 (TOE1), TOE2, TOE3, SCHLAFMÜTZE (SMZ) and SCHNARCHZAPFEN (SNZ) (Aukerman and Sakai 2003; Chen 2004; Spanudakis and Jackson 2014).

Warm ambient temperature $\left(27^{\circ} \mathrm{C}\right.$ ) reduces the expression of miR169 (Gyula et al. 2018), which target mRNAs encoding subunits A of the NUCLEAR FACTOR $\mathrm{Y}(\mathrm{NF}-\mathrm{Y})$ transcription factor complex. These TF form a conserved heterotrimeric TF complex that is composed of NF-Y subunit A (NF-YA), NF-YB and NF-YC subunits (Petroni et al. 2012). The miR169 family represses the NF-YA subunit, which affects the expression of the NF-Y -dependent genes, including the flowering time regulator FLOWERING LOCUS T $(F T)$, the auxin synthesis gene YUC2, and could mediate the high ambient temperature-induced early flowering (Gyula et al. 2018; Siriwardana et al. 2016).

PHYTOCHROME B (PHYB) mediates red light and high ambient temperature signals through a subset of basic helix-loop-helix (b-HLH) transcription factors, the PHYTOCHROME INTERACTING FACTOR1 (PIF1), PIF3, PIF4 and PIF5 (Jung et al. 2016; Legris et al. 2016). PIF4 is a key regulator of the photo- and thermomorphogenesis. At high ambient temperature, the PIF4 alters the expression of hundreds of genes that result in morphological and physiological changes that are necessary for thermal adaptation. A recent study described a new, surprising function of this transcription factor (Sun et al. 2018). According to this, PIF4 not only regulates the transcription of some miRNA genes, but being the part of the Microprocessor complex, it affects the cleavage of the miRNA duplex from the miRNA-precursor in a red light-, and probably a temperature-regulated manner by promoting the degradation of DCL1 and HYL1 proteins. This moonlighting activity of PIF4 suggests that other bHLH proteins may also bind the DCL1 and HYL1 conveying other environmental or hormonal signals to the Microprocessor complex. Temperature affects miRNA processing at multiple levels; at low ambient temperature $\left(16^{\circ} \mathrm{C}\right)$, the miRNA processing machinery becomes more robust and it does not require the presence of DCL1 cofactors HYL1 and SE, for short base-to-loop processing of miRNA precursor (Re et al. 2019). 


\section{5 sRNAs Regulate Thermotolerance Response}

Many sRNA (like miR156, miR160, miR164, miR166, miR169, miR171, miR319, miR398 or TAS1-derived ta-siRNAs) are also induced in response to heat (see Table 9.1). Heat-induced changes of miR160 contribute to thermotolerance through alteration of HSP expression. High-throughput sequencing and hybridization experiments have revealed that induction of miR160 occurs in various plant species (Kruszka et al. 2014; Kumar et al. 2015; Lin et al. 2018). HS induced miR160 transcriptionally, that caused repression of AUXIN RESPONSIVE FACTOR 10 (ARF10), ARF16 and ARF17 targets (Lin et al. 2018). Auxin decrease during heat also contributes to ARF10 and ARF16 repression through a miR160-independent pathway (Wang et al. 2005). Downregulation of ARFs was necessary for proper HSR: overexpression of miR160 improved seed germination and seedling survival in response to heat while miR160-mimicry plants became HS-sensitive (Lin et al. 2018). The HS-tolerant phenotype of arf10, arf16, and arfl7 mutant plants was similar to miR160-overexpressors. miR160's and ARFs' changes during HS alter the expression of multiple HSPs. Therefore, the intertwined activities of hormonal signals, protein homeostasis, and miR160-guided silencing contribute to basal thermotolerance in a positive manner. Some miRNAs might affect HS tolerance negatively. miR400 is a negative regulator of HS response in Arabidopsis. ath-miR400 is located within an intron and is co-transcribed with its host nascent RNA transcript. Under non-inductive conditions, the miR400-containing intron is spliced, and the miR400 maturated from this intron/precursor. Under HS conditions, alternative splicing of host genes led to partial intron retention and abolishment of miR400 processing (the level of the host gene was not affected). Overexpression of miR400 causes HS-sensitive phenotype, therefore, downregulation of miR400 is required for proper thermotolerance response (Yan et al. 2012). Alternative splicing, therefore, regulates HS response via the miRNA pathway.

miR159 has also a negative impact on HSR. It was shown that luffa (Luffa cylindrica) rootstock enhanced thermotolerance in cucumber (Cucumis sativus) plants (Li et al. 2016a). Luffa rootstock induced a significant downregulation of a subset of miRNAs in the shoot during HS, suggesting that miRNAs might participate in luffa rootstock-induced heat tolerance. Amongst these, miR156, miR159, miR169, and miR398 were linked to HS response previously (Guan et al. 2013; Kruszka et al. 2014; Xin et al. 2010). Luffa rootstock also induced enhanced abscisic acid (ABA) accumulation in the shoot. It is known that ABA plays a role in the regulation of several miRNAs, such as miR159. miR159 targets are the MYB transcription factors that are involved in abiotic stress responses. Foliar application of exogenous ABA suppressed miR159 and induced CsMYB29-like and CsGAMYB1 target levels (Li et al. 2016a). Transgenic tae-miR159-overexpressor rice, csa-miR159-overexpressor, and myb33;myb65 double mutant Arabidopsis plants were shown to be HS-sensitive (Li et al. 2016a; Wang et al. 2012). AtHSP70 transcript and protein accumulation were impaired in miR159b overexpression lines suggesting that HSP70 may be directly or 
indirectly, negatively regulated by miR 159 under natural conditions. miR159 downregulation, therefore, is required for efficient HSR. It was suggested that cucumber plants that originate in the temperate climate have evolved poor HSR compared to luffa plants. However, the role of the Arabidopsis miR159-MYB33/65 pathway in abiotic stress responses including heat was questioned by another study (Li et al. 2016b).

The decrease of ta-siRNAs is also required for proper HSR. It has been shown that targets of TAS1-derived ta-siRNA, named HEAT-INDUCED TAS1 TARGET1 (HTT1) and HTT2 regulate thermotolerance (Li et al. 2014b). HTT1 and HTT2 are strongly accumulated during HS due to the direct HSFA1s-mediated transcriptional activation. Parallel to this, HS inhibited the production of TAS1-derived ta-siRNAs, the negative regulators of HTT1 and HTT2 that contributed to the elevated level of HTT1 and HTT2 under HS conditions. Overexpression of TAS1 a reduced expression of HTT genes and caused HS-sensitive phenotype while overexpression of HTT1 and HTT2 upregulated several HSF genes and improved thermotolerance of transgenic plants. HTT1 and HTT2 positively regulate HSR through transcriptional activation of HS-related targets within a transcriptional complex comprising HSP70-14, HSP40, and NF-Y complex subunit C2 (NF-YC2) factors.

\subsection{Role of sRNAs in Acquired Thermotolerance and Heat Stress Memory}

Stress events are recurring in nature. The encounter of nonlethal stress leads to the acquisition of thermotolerance (acquired thermotolerance or AT). AT functions to prime the plants for a quicker and/or stronger HSR during later, more severe stresses and to alter post-stress development of plants in order to be able to complete the life cycle before lethal stress (e.g. modulate growth rate, flowering time, senescence, etc.). agol mutant plants are impaired in acquired thermotolerance suggesting the involvement of RNA silencing pathway also in this form of the stress response (Stief et al. 2014). AGO1 levels might be modulated in response to heat through an autoregulatory loop involving miR168 activity (Chen et al. 2012; Hivrale et al. 2016; Vaucheret et al. 2006; Xin et al. 2010).

miRNAs and ta-siRNA classes are both involved in AT. The miR156 family is highly conserved (Cui et al. 2014; Stief et al. 2014) and controls juvenile to adult transition. miR156 is strongly induced transcriptionally during heat stress and its activation persists for several days (Stief et al. 2014). miR156 family downregulates SPLs to promote sustained expression of heat-stress memory-related genes including APX2, sHSP17.6A, HSFA2, HSA32, sHSP22. The expression of MIR156 genes following HS is critical for acquired thermotolerance and heat stress memory. Epigenetic modifications like $\mathrm{H} 3 \mathrm{~K} 4 \mathrm{me} 2 / 3$ are involved in transcriptional memory (Lamke et al. 2016). 
The most deleterious impact of heat is caused during the reproductive phase of plant life. Flowers are the most heat-susceptible tissues: heat affects pollen viability, grain filling, and maturation. Through all these, HS compromises reproductive success (Liu et al. 2017; Stief et al. 2014). Flowering time, therefore, is regulated in a complex manner to align it to the most favorable environmental conditions. miR156 is a repressor, miR172 is an activator of flowering time through age pathway (Wang 2014). The decline of the miR156 level with aging provides a permissive environment for flowering through de-repression of SPLs that positively regulate floral activator genes including LEAFY, FRUITFULL, APETALA1, APETALA2 or FT (Kim et al. 2012; Wang et al. 2009; Yamaguchi et al. 2009). Bra-miR156 upregulation and BraSPL2 downregulation also occur in B. rapa (Yu et al. 2012). Heat $\left(37-45^{\circ} \mathrm{C}\right)$ not only induces miR156 but also represses miR172 in Arabidopsis, wheat, or Helianthus annuus (Ebrahimi Khaksefidi et al. 2015; May et al. 2013; Stief et al. 2014; Xin et al. 2010) while its targets are upregulated. Antagonistic changes of miR156-SPL and miR172-AP2 regulatory modules converge to record plant age as "time well spent" (excluding stress time) (Stief et al. 2014) and modulate flowering time accordingly.

miR319 also contributes to flowering time changes in response to HS. The miR319 family targets TEOSINTE BRANCHED/CYCLOIDEA/PCF domain proteins (TCPs). TCPs are positive regulators of flowering time: overexpression of miR319 and loss-of-function of the miR319 target TCP4 cause late flowering. miR319 is upregulated and TCP family genes are downregulated during HS (Hivrale et al. 2016). ta-siRNAs also affect flowering time regulation (Liu et al. 2019) (see later). In summary, the spectrum of sRNAome fine-tunes stress response both through positive and negative activities in order to mitigate the detrimental impact of heat and successfully accomplish reproduction.

\section{7 sRNAs Are Required for Trans-Generational Stress Memory}

Temperature affects the efficiency of RNA silencing (Szittya et al. 2003; Zhong et al. 2013). Moderate heat stress $\left(30^{\circ} \mathrm{C}\right)$ induces the epigenetic release of RNA silencing through inhibition of ta-siRNA biogenesis (Zhong et al. 2013). It was shown recently that this pathway requires the activity of HSFA2, REF6, and SGIP1 (Liu et al. 2019). HSFA2 transcriptionally activates RELATIVE OF EARLY FLOWERING 6 (REF6), an H3K27-demethylase gene (Lu et al. 2011). REF6, in turn, de-represses HSFA2, through H3K27me3 demethylation. As a consequence, it is established a heritable feedback loop that positively affects both heat response and thermomemory. REF6-HSFA2 interplay activates SGS3-INTERACTING PROTEIN 1 (SGIP1), an E3 ubiquitin ligase. SGIP1 mediates degradation of SUPPRESSOR OF GENE SILENCING (SGS3) protein (Kumakura et al. 2009; Mourrain et al. 2000), the cofactor of RDR6. SGS3 degradation leads to the abolishment of ta-siRNA production in 
the heat-stressed plants. Low levels of SGS3 are epigenetically maintained also in the non-stressed progeny (Liu et al. 2019; Zhong et al. 2013). HS-induced transcriptional activation and absence of ta-siRNAs activity converge to release HTT5, which drives early flowering (Liu et al. 2019). The basis for trans-generational adaptation is the maternally transmitted $\mathrm{H} 3 \mathrm{~K} 27 \mathrm{me} 3$ demethylation of the HSFA2 locus.

Besides the PTGS pathway, RdDM-mediated TGS also plays a role in the defense against the detrimental effects of excessive heat. It has been shown that under heat stress, the Copia-type retrotransposon ONSEN is transcriptionally activated and produces extrachromosomal DNA copies (Ito et al. 2011). HS-induction of ONSEN requires HSE cis motifs and HSFA1s and HSFA2 trans factors (Pecinka et al. 2010). Activation of ONSEN was stimulated in siRNA biogenesis mutants: a high frequency of new ONSEN insertions was observed in the progeny of stressed siRNA-deficient plants. As retrotransposition was not observed in wild-type plants subjected to the same treatment (Ito et al. 2011), siRNA pathway has a crucial role in restricting stress-triggered retrotransposition ensuring genome stability during and following heat stress. Transient derepression of ONSEN may result occasionally in new retrotransposition events. Heat-induced trans-generational trait changes via ta-siRNA and het-siRNA pathway may offer adaptive advantage and flexibility amongst warmer environments.

Trans-generational thermomemory, however, can be associated with negative consequences: the release of HTT5 in absence of ta-siRNAs attenuated plants' immunity. Abiotic resistance might also affect growth rate amongst non-stress conditions or in response to different stresses. Therefore it is conceivable that unknown mechanisms hamper full inheritance of epigenetic traits. Chromatin regulators DECREASE IN DNA METHYLATION1 (DDM1) and MORPHEUS' MOLECULE1 (MOM1) were found to redundantly prevent transgenerational inheritance of environmentally induced traits (Iwasaki and Paszkowski 2014). In accordance with this idea, ta-siRNA biogenesis and basal level of thermoresistance were reset in later generations (Liu et al. 2019), providing flexibility for adaptation in the long term.

\subsection{A Complex sRNA Network Contributes to HSR}

The above examples (see also Table 9.1) illustrate that under elevated ambient temperature $\left(27-29^{\circ} \mathrm{C}\right)$ and heat stress $\left(32-45^{\circ} \mathrm{C}\right)$ conditions a number of sRNAs are changed to coordinate temperature response. The altered sRNAome causes changes in the mRNA target network that affects a large spectrum of cellular and physiological processes. Under optimal conditions, resources are directed to support growth and development. Under elevated ambient temperatures, stress responses are already initiated but at the same time, the flowering transition is accelerated to ensure reproductive success: the cost of this is that fewer seeds are produced. During severe stress, growth and development are rather stalled and resources are primarily mobilized to manage the negative impacts of stress. The trade-off between development 
and stress response is continuously fine-tuned based on the strength, type and duration of temperature changes encountered.

The miR156-SPL9-DFR pathway was suggested to coordinate the balance between growth and abiotic stress tolerance in Arabidopsis (Cui et al. 2014). Under optimal conditions, miR156 is suppressed to accelerate development, while under stress conditions it is induced to maintain juvenile state for a longer period. The mechanism is conserved also in rice. Downstream genes that take part in this include miR156-targets SPL9 and DIHYDROFLAVONOL-4-REDUCTASE (DFR) that modulate anthocyanin metabolism. miR156 is induced in response to multiple abiotic stresses including heat, salt or mannitol. SPL9 and SPL10 targets of miR156 promote transcription of miR172 that is required for the juvenile-to-adult transition. miR172 overexpression cause stress-sensitivity, further supporting the antagonistic relationship between development and stress response.

Auxin perception and signaling pathway also attenuate growth through miRNA activity. Expression of auxin-responsive genes is mediated by the auxin receptor TRANSPORT INHIBITOR RESPONSE 1 (TIR1) through ARFs release from auxinmediated heterodimerization. miR393 negatively regulates TIR1, while miR160 and miR167 negatively regulate ARFs. Upon stress, miR160 is induced, it downregulates ARF10, ARF16, and ARF17 leading to suppression of ARF-induced gene expression and thereby growth attenuation (Sunkar et al. 2012). Upregulation of miR160 and parallel downregulation of ARF targets was also observed in barley and H. annuиs (Ebrahimi Khaksefidi et al. 2015; Kruszka et al. 2014). In wheat, however, miR160 was downregulated in response to heat (Kumar 2014). Besides these, miR390 and miR393 also participates in auxin-mediated HSR (Hivrale et al. 2016; Vidal et al. 2010).

The miR166 target PHAVOLUTA (PHV), REVOLUTA (REV), and HOMEOBOX LEUCINE ZIPPER PROTEIN 9 (HOX9) and miR319 target TCP are involved in leaf development; miR171 targets SCARECROW-LIKE6s (SCL6s) and miR164 target NAC1 regulate shoot and root development; all these miRNAs are induced and their targets are repressed in response to heat (Mahale et al. 2013; Kruszka et al. 2014; Schommer et al. 2008), further underpinning the hypothesis that developmental pathways are being retarded temporarily to allow stress recovery.

In summary, combined sRNA changes contribute to the balance between growth and stress response and aim completion of life-cycle to establish the next generation (Fig. 9.1).

\subsection{Combined Stress Pathways Are Regulated by sRNAs}

In nature, abiotic stresses occur mostly in combination. Multiple miRNAs, including the above-mentioned miRNAs (miR156, miR160, miR167, and miR393) are upregulated or downregulated in response to heat, cold, salt, mannitol, UV-B, drought, hypoxia or oxidative stress in diverse species (Khraiwesh et al. 2012). This suggests 
that miRNAs are integrators of environmental stimuli under combined environmental stress conditions.

Exposure to high temperature causes oxidative stress as well. Signals generated during oxidative stress are absolutely required for an effective HSR (Dickinson et al. 2018). Subcellular energy organelles, the chloroplasts, drive a series of metabolic reprogramming (Wang et al. 2018) and initiate multiple retrograde signaling to regulate abiotic (light, heat, oxidative) stress responses (Dickinson et al. 2018; Fang et al. 2019). One of these pathways acts through miRNAs (Fang et al. 2019): plastid synthesized tocopherols and $3^{\prime}$-phosphoadenosine 5'-phosphate (PAP) inhibit nuclear exoribonucleases (XRN)-catalyzed pri-miRNA degradation. This promotes enhanced miRNA biogenesis, amongst others that of miR398 that confers thermotolerance to the plants. Efficient accumulation of miR398 also requires transcriptional induction via direct binding of HSFA1b and HSFA7b to its gene promoter region (Guan et al. 2013). As a consequence, the level of miR398 targets Cu/Zn SUPEROXIDE DISMUTASE 1 (CSD1), CSD2, and COPPER CHAPERONE FOR SUPEROXIDE DISMUTASE (CCS) mRNAs are downregulated in response to heat (Guan et al. 2013). Transgenic plants expressing miR398-resistant forms of CSD1, CSD2, and CCS are HS-sensitive and expression of numerous HSFs and HSPs during the heat is reduced. Oppositely to this, $c s d 1, c s d 2$, and $c c s$ mutant plants are HS-resistant and expression of certain HSFs and HSPs is induced. It was suggested that heatinduced miR398 alters cellular redox status through negative regulation of CSD1, CSD2 and CCS targets. The altered redox environment is directly or indirectly sensed by HSFs (Volkov et al. 2006) and thermotolerance pathways are initiated through HSR-regulon. miR398 family members and their target genes are highly conserved across monocots and dicots. miR398 heat-induction was found to occur also in maize, Brassica rapa and Populus tomentosa (Guan et al. 2013; Kotak et al. 2007; Yu et al. 2012).

Another miRNA, miR408, also contributes to redox changes during different abiotic stress conditions. Expression of miR408 is significantly induced by abiotic stresses including heat (also cold, salt, oxidative, osmotic drought) in Arabidopsis and important crop plants. miR408 targets are the PHYTOCYANIN family genes that function as electron-transfer factors to regulate redox state (Hivrale et al. 2016; Kumar et al. 2015; Ma et al. 2015; Mangrauthia et al. 2017; Zhou et al. 2016). miR398 and miR408, therefore, may provide abiotic stress tolerance through regulation of redox status during heat or combined stress conditions. Manipulation of redox state through alteration of miR398, miR408 or their targets, therefore, may be a useful strategy to breed thermotolerant crops.

\subsection{Breeding for Thermotolerance}

In order to enhance HS tolerance in crop plants, it is necessary to better understand the molecular mechanisms that regulate the HSR and to develop new breeding strategies. In a large number of studies, the biological relevance of sRNA and target changes in 
HSR has been demonstrated using sRNA or target mutants, miRNA-overexpressors, or target-mimicry lines. These findings spurred the idea of developing crops having altered miRNA or target level leading to improved agronomical performance, yield or nutritional value amongst abiotic (e.g. heat stress) conditions. This may be achieved through classical or molecular breeding. Artificial miRNAs (amiRNA) have been successfully employed to silence endogenous targets in model plants, crop plants and unicellular organisms (Alvarez et al. 2006; Khraiwesh et al. 2008; Molnar et al. 2009; Schwab et al. 2006; Warthmann et al. 2008). amiRNAs may be designed to have high specificity (avoid off-target effects). Oppositely to amiRNA technology that suppresses target levels, target-mimicry constructs lead to the abolishment of miRNA activity and consequently target-mRNA accumulation (Franco-Zorrilla et al. 2007). amiRNAs and target-mimicry constructs provide a flexible tool for downregulation of related genes or gene families. In contrast to miRNA-based methods, siRNA-based RNA silencing technology (RNA interference or RNAi) cannot be successfully employed for heat-tolerant plant breeding since these depend on the activity of RDR6/SGS3 complex (SGS3 protein is degraded under high-temperature conditions) (Liu et al. 2019) for amplification of gene silencing response. At the same time, it is important to consider the possible side-effect of the improved abiotic tolerance: improved heat-tolerance weakens immunity and might cause poor development under non-stress conditions (Liu et al. 2019).

\subsection{Conclusions}

There is an increased risk of crop yield reduction worldwide caused by global warming and extreme temperature fluctuations. Elucidation of temperature response, therefore, is becoming more important. Present evidence suggests that epigenetic, transcriptional, sRNA-mediated post-transcriptional and protein-level regulatory mechanisms are all intercalated to precisely and flexibly adjust the trade-off between development and stress response within and trans-generationally. Future research is needed for functional confirmation of HS-responsive sRNA/target changes and for the elucidation of the relationship of sRNA-mediated HSR and other regulatory networks. Complete understanding of the mechanism of sRNA action during HS, combined abiotic stresses or cross-protection between stresses may provide tools for breeding resilient crops.

Acknowledgements H.M.Sz. is a Ph.D. student at the Eötvös Loránd University, Budapest, Faculty of Natural Sciences; T.Cs. was supported by János Bolyai Research Scholarship of Hungarian Academy of Science and Hungarian National Research, Development and Innovation Office, K115934 and K-129283. G.S. is funded by grants from Hungarian National Research, Development and Innovation Office, K-119701 and K-129171. 


\section{References}

Alvarez JP, Pekker I, Goldshmidt A, Blum E, Amsellem Z, Eshed Y (2006) Endogenous and synthetic microRNAs stimulate simultaneous, efficient, and localized regulation of multiple targets in diverse species Plant Cell 18:1134-1151. https://doi.org/10.1105/tpc.105.040725

Aukerman MJ, Sakai H (2003) Regulation of flowering time and floral organ identity by a MicroRNA and its APETALA2-like target genes. Plant Cell 15:2730-2741. https://doi.org/10.1105/tpc. 016238

Axtell MJ (2013) Classification and comparison of small RNAs from plants. Annu Rev Plant Biol 64:137-159. https://doi.org/10.1146/annurev-arplant-050312-120043

Baksa I et al (2015) Identification of Nicotiana benthamiana microRNAs and their targets using high throughput sequencing and degradome analysis BMC genomics 16:1025. https://doi.org/10. 1186/s12864-015-2209-6

Ballen-Taborda C, Plata G, Ayling S, Rodriguez-Zapata F, Becerra Lopez-Lavalle LA, Duitama J, Tohme J (2013) Identification of Cassava MicroRNAs under abiotic stress. Int J Genomics 2013:857986. https://doi.org/10.1155/2013/857986

Barciszewska-Pacak M et al (2015) Arabidopsis microRNA expression regulation in a wide range of abiotic stress responses. Front Plant Sci 6:410. https://doi.org/10.3389/fpls.2015.00410

Beckers M, Mohorianu I, Stocks M, Applegate C, Dalmay T, Moulton V (2017) Comprehensive processing of high-throughput small RNA sequencing data including quality checking, normalization, and differential expression analysis using the UEA sRNA. Workbench RNA 23:823-835. https://doi.org/10.1261/rna.059360.116

Bilichak A, Ilnytskyy Y, Woycicki R, Kepeshchuk N, Fogen D, Kovalchuk I (2015) The elucidation of stress memory inheritance in Brassica rapa plants. Front Plant Sci 6:5. https://doi.org/10.3389/ fpls.2015.00005

Borges F, Martienssen RA (2015) The expanding world of small RNAs in plants. Nat Rev Mol Cell Biol 16:727-741. https://doi.org/10.1038/nrm4085

Brzezinka K et al (2016) Arabidopsis FORGETTER1 mediates stress-induced chromatin memory through nucleosome remodeling. eLife 5. https://doi.org/10.7554/elife.17061

Brzezinka K, Altmann S, Baurle I (2018) BRUSHY1/TONSOKU/MGOUN3 is required for heat stress memory. Plant Cell Environ. https://doi.org/10.1111/pce.13365

Chan-Schaminet KY, Baniwal SK, Bublak D, Nover L, Scharf KD (2009) Specific interaction between tomato HsfA1 and HsfA2 creates hetero-oligomeric superactivator complexes for synergistic activation of heat stress gene expression. J Biol Chem 284:20848-20857. https://doi.org/ 10.1074/jbc.m109.007336

Charng YY, Liu HC, Liu NY, Hsu FC, Ko SS (2006) Arabidopsis Hsa32, a novel heat shock protein, is essential for acquired thermotolerance during long recovery after acclimation. Plant Physiol 140:1297-1305. https://doi.org/10.1104/pp.105.074898

Charng YY, Liu HC, Liu NY, Chi WT, Wang CN, Chang SH, Wang TT (2007) A heat-inducible transcription factor, HsfA2, is required for extension of acquired thermotolerance in Arabidopsis. Plant Physiol 143:251-262. https://doi.org/10.1104/pp.106.091322

Chen X (2004) A microRNA as a translational repressor of APETALA2 in Arabidopsis flower development. Science 303:2022-2025. https://doi.org/10.1126/science.1088060

Chen L, Ren Y, Zhang Y, Xu J, Sun F, Zhang Z, Wang Y (2012) Genome-wide identification and expression analysis of heat-responsive and novel microRNAs in Populus tomentosa. Gene 504:160-165. https://doi.org/10.1016/j.gene.2012.05.034

Cortijo S et al (2017) Transcriptional regulation of the ambient temperature response by H2A.Z nucleosomes and HSF1 transcription factors in Arabidopsis. Mol Plant 10:1258-1273. https:// doi.org/10.1016/j.molp.2017.08.014

Cui LG, Shan JX, Shi M, Gao JP, Lin HX (2014) The miR156-SPL9-DFR pathway coordinates the relationship between development and abiotic stress tolerance in plants. Plant J Cell Mol Biol 80:1108-1117. https://doi.org/10.1111/tpj.12712 
Dalmay T, Hamilton A, Rudd S, Angell S, Baulcombe DC (2000) An RNA-dependent RNA polymerase gene in Arabidopsis is required for posttranscriptional gene silencing mediated by a transgene but not by a virus. Cell 101:543-553

Dickinson PJ et al (2018) Chloroplast signaling gates thermotolerance in Arabidopsis. Cell Rep 22:1657-1665. https://doi.org/10.1016/j.celrep.2018.01.054

Ebrahimi Khaksefidi R et al (2015) Differential expression of seven conserved microRNAs in response to abiotic stress and their regulatory network in Helianthus annuиs. Front Plant Sci 6:741. https://doi.org/10.3389/fpls.2015.00741

Fang X et al (2019) Chloroplast-to-nucleus signaling regulates microRNA biogenesis in Arabidopsis. Dev Cell 48(371-382):e374. https://doi.org/10.1016/j.devcel.2018.11.046

Franco-Zorrilla JM et al (2007) Target mimicry provides a new mechanism for regulation of microRNA activity. Nat Genet 39:1033-1037. https://doi.org/10.1038/ng2079

Giacomelli JI, Weigel D, Chan RL, Manavella PA (2012) Role of recently evolved miRNA regulation of sunflower HaWRKY6 in response to temperature damage. New Phytologist 195:766-773. https://doi.org/10.1111/j.1469-8137.2012.04259.x

Guan Q, Lu X, Zeng H, Zhang Y, Zhu J (2013) Heat stress induction of miR398 triggers a regulatory loop that is critical for thermotolerance in Arabidopsis. Plant J Cell Mol Biol 74:840-851. https:// doi.org/10.1111/tpj.12169

Gyula P, Baksa I, Toth T, Mohorianu I, Dalmay T, Szittya G (2018) Ambient temperature regulates the expression of a small set of sRNAs influencing plant development through NF-YA2 and YUC2. Plant Cell Environ 41:2404-2417. https://doi.org/10.1111/pce.13355

He F, Xu C, Fu X, Shen Y, Guo L, Leng M, Luo K (2018) The microRNA390/TRANS ACTING SHORT INTERFERING RNA3 module mediates lateral root growth under salt stress via the auxin pathway. Plant Physiol. https://doi.org/10.1104/pp.17.01559

Hivrale V et al (2016) Characterization of drought- and heat-responsive microRNAs in switchgrass. Plant Sci Int J Experim Plant Biol 242:214-223. https://doi.org/10.1016/j.plantsci.2015.07.018

Ito H, Gaubert H, Bucher E, Mirouze M, Vaillant I, Paszkowski J (2011) An siRNA pathway prevents transgenerational retrotransposition in plants subjected to stress. Nature 472:115-119. https://doi.org/10.1038/nature09861

Iwasaki M, Paszkowski J (2014) Identification of genes preventing transgenerational transmission of stress-induced epigenetic states. Proc Natl Acad Sci USA 111:8547-8552. https://doi.org/10. 1073/pnas.1402275111

Jeong DH, Park S, Zhai J, Gurazada SG, De Paoli E, Meyers BC, Green PJ (2011) Massive analysis of rice small RNAs: mechanistic implications of regulated microRNAs and variants for differential target RNA cleavage. Plant Cell 23:4185-4207. https://doi.org/10.1105/tpc.111.089045

Jung JH et al (2016) Phytochromes function as thermosensors in Arabidopsis. Science 354:886-889. https://doi.org/10.1126/science.aaf6005

Khraiwesh B, Ossowski S, Weigel D, Reski R, Frank W (2008) Specific gene silencing by artificial MicroRNAs in Physcomitrella patens: an alternative to targeted gene knockouts. Plant Physiol 148:684-693. https://doi.org/10.1104/pp.108.128025

Khraiwesh B, Zhu JK, Zhu J (2012) Role of miRNAs and siRNAs in biotic and abiotic stress responses of plants. Biochem Biophys Acta 1819:137-148. https://doi.org/10.1016/j.bbagrm. 2011.05.001

Kim W, Ahn HJ, Chiou TJ, Ahn JH (2011) The role of the miR399-PHO2 module in the regulation of flowering time in response to different ambient temperatures in Arabidopsis thaliana. Mol Cells 32:83-88. https://doi.org/10.1007/s10059-011-1043-1

Kim JJ, Lee JH, Kim W, Jung HS, Huijser P, Ahn JH (2012) The microRNA156-SQUAMOSA PROMOTER BINDING PROTEIN-LIKE3 module regulates ambient temperature-responsive flowering via FLOWERING LOCUS T in Arabidopsis. Plant Physiol 159:461-478. https://doi. org/10.1104/pp.111.192369

Kim W, Kim HE, Jun AR, Jung MG, Jin S, Lee JH, Ahn JH (2016) Structural determinants of miR156a precursor processing in temperature-responsive flowering in Arabidopsis. J Experim Botany 67:4659-4670. https://doi.org/10.1093/jxb/erw248 
Kotak S, Larkindale J, Lee U, von Koskull-Doring P, Vierling E, Scharf KD (2007) Complexity of the heat stress response in plants. Curr Opin Plant Biol 10:310-316. https://doi.org/10.1016/j. pbi.2007.04.011

Kruszka K et al (2014) Transcriptionally and post-transcriptionally regulated microRNAs in heat stress response in barley. J Exp Bot 65:6123-6135. https://doi.org/10.1093/jxb/eru353

Kumakura N, Takeda A, Fujioka Y, Motose H, Takano R, Watanabe Y (2009) SGS3 and RDR6 interact and colocalize in cytoplasmic SGS3/RDR6-bodies. FEBS Lett 583:1261-1266. https:// doi.org/10.1016/j.febslet.2009.03.055

Kumar R (2014) Role of microRNAs in biotic and abiotic stress responses in crop plants. Appl Biochem Biotechnol 174:93-115. https://doi.org/10.1007/s12010-014-0914-2

Kumar RR et al (2015) Novel and conserved heat-responsive microRNAs in wheat (Triticum aestivum L.). Funct Integr Genom 15:323-348. https://doi.org/10.1007/s10142-014-0421-0

Lamke J, Brzezinka K, Altmann S, Baurle I (2016) A hit-and-run heat shock factor governs sustained histone methylation and transcriptional stress memory. EMBO J 35:162-175. https://doi.org/10. 15252/embj.201592593

Lee $\mathrm{H}$ et al (2010) Genetic framework for flowering-time regulation by ambient temperatureresponsive miRNAs in Arabidopsis. Nucl Acids Res 38:3081-3093. https://doi.org/10.1093/nar/ gkp1240

Legris M et al (2016) Phytochrome B integrates light and temperature signals in Arabidopsis. Science 354:897-900. https://doi.org/10.1126/science.aaf5656

Li MY, Wang F, Xu ZS, Jiang Q, Ma J, Tan GF, Xiong AS (2014a) High throughput sequencing of two celery varieties small RNAs identifies microRNAs involved in temperature stress response. BMC genomics 15:242. https://doi.org/10.1186/1471-2164-15-242

Li S, Liu J, Liu Z, Li X, Wu F, He Y (2014b) HEAT-INDUCED TAS1 TARGET1 mediates thermotolerance via HEAT STRESS TRANSCRIPTION FACTOR A1a-directed pathways in Arabidopsis. Plant Cell 26:1764-1780 https://doi.org/10.1105/tpc.114.124883

$\mathrm{Li} \mathrm{H}$ et al (2016a) Microarray and genetic analysis reveals that csa-miR159b plays a critical role in abscisic acid-mediated heat tolerance in grafted cucumber plants. Plant Cell Environ 39:17901804. https://doi.org/10.1111/pce. 12745

Li Y, Alonso-Peral M, Wong G, Wang MB, Millar AA (2016b) Ubiquitous miR159 repression of MYB33/65 in Arabidopsis rosettes is robust and is not perturbed by a wide range of stresses. BMC Plant Biol 16:179. https://doi.org/10.1186/s12870-016-0867-4

Lin JS et al (2018) MicroRNA160 modulates plant development and heat shock protein gene expression to mediate heat tolerance in Arabidopsis. Front Plant Sci 9:68. https://doi.org/10. 3389/fpls.2018.00068

Lin MY, Chai KH, Ko SS, Kuang LY, Lur HS, Charng YY (2014) A positive feedback loop between HEAT SHOCK PROTEIN101 and HEAT STRESS-ASSOCIATED 32-KD PROTEIN modulates long-term acquired thermotolerance illustrating diverse heat stress responses in rice varieties. Plant Physiol 164:2045-2053. https://doi.org/10.1104/pp.113.229609

Liu J et al (2019) An H3K27me3 demethylase-HSFA2 regulatory loop orchestrates transgenerational thermomemory in Arabidopsis. Cell Res. https://doi.org/10.1038/s41422-019-0145-8

Liu HC, Charng YY (2012) Acquired thermotolerance independent of heat shock factor A1 (HsfA1), the master regulator of the heat stress response. Plant Signal Behav 7:547-550. https://doi.org/ 10.4161/psb. 19803

Liu HC, Charng YY (2013) Common and distinct functions of Arabidopsis class A1 and A2 heat shock factors in diverse abiotic stress responses and development. Plant Physiol 163:276-290. https://doi.org/10.1104/pp.113.221168

Liu HC, Liao HT, Charng YY (2011) The role of class A1 heat shock factors (HSFA1s) in response to heat and other stresses in Arabidopsis. Plant Cell Environ 34:738-751. https://doi.org/10.1111/ j.1365-3040.2011.02278.x

Liu F, Wang W, Sun X, Liang Z, Wang F (2013) RNA-Seq revealed complex response to heat stress on transcriptomic level in Saccharina japonica (Laminariales, Phaeophyta). J Appl Phycol 26(3):1585-1596 
Liu Q et al (2017) Integrating small RNA sequencing with QTL mapping for identification of miRNAs and their target genes associated with heat tolerance at the flowering stage in rice. Front Plant Sci 8:43. https://doi.org/10.3389/fpls.2017.00043

Liu HC, Lamke J, Lin SY, Hung MJ, Liu KM, Charng YY, Baurle I (2018) Distinct heat shock factors and chromatin modifications mediate the organ-autonomous transcriptional memory of heat stress. Plant J Cell Mol Biol. https://doi.org/10.1111/tpj.13958

Lu S, Sun YH, Chiang VL (2008) Stress-responsive microRNAs in Populus. Plant J Cell Mol Biol 55:131-151. https://doi.org/10.1111/j.1365-313X.2008.03497.x

Lu F, Cui X, Zhang S, Jenuwein T, Cao X (2011) Arabidopsis REF6 is a histone H3 lysine 27 demethylase. Nat Genet 43:715-719. https://doi.org/10.1038/ng.854

Luria G, Rutley N, Lazar I, Harper JF, Miller G (2019) Direct analysis of pollen fitness by flow cytometry: implications for pollen response to stress. Plant J Cell Mol Biol. https://doi.org/10. $1111 /$ tpj. 14286

Ma C, Burd S, Lers A (2015) miR408 is involved in abiotic stress responses in Arabidopsis. Plant J Cell Mol Biol 84:169-187. https://doi.org/10.1111/tpj.12999

Mahale BM, Fakrudin B, Ghosh S, Krishnaraj PU (2013) LNA mediated in situ hybridization of miR171 and miR397a in leaf and ambient root tissues revealed expressional homogeneity in response to shoot heat shock in Arabidopsis thaliana. J Plant Biochem Biotechnol 23(1):93-103

Mangrauthia SK, Bhogireddy S, Agarwal S, Prasanth VV, Voleti SR, Neelamraju S, Subrahmanyam D (2017) Genome-wide changes in microRNA expression during short and prolonged heat stress and recovery in contrasting rice cultivars. J Exp Bot 68:2399-2412. https://doi.org/10.1093/jxb/ erx111

Martinez de Alba AE, Elvira-Matelot E, Vaucheret H (2013) Gene silencing in plants: a diversity of pathways. Biochimica et biophysica acta 1829:1300-1308. https://doi.org/10.1016/j.bbagrm. 2013.10.005

Maruyama K et al (2017) Design of an optimal promoter involved in the heat-induced transcriptional pathway in Arabidopsis, soybean, rice and maize. Plant J Cell Mol Biol 89:671-680. https://doi. org/10.1111/tpj.13420

May P, Liao W, Wu Y, Shuai B, McCombie WR, Zhang MQ, Liu QA (2013) The effects of carbon dioxide and temperature on microRNA expression in Arabidopsis development. Nat Commun 4:2145. https://doi.org/10.1038/ncomms3145

Mazzeo MF, Cacace G, Iovieno P, Massarelli I, Grillo S, Siciliano RA (2018) Response mechanisms induced by exposure to high temperature in anthers from thermo-tolerant and thermo-sensitive tomato plants: a proteomic perspective. PloS one 13:e0201027. https://doi.org/10.1371/journal. pone.0201027

Meiri D, Breiman A (2009) Arabidopsis ROF1 (FKBP62) modulates thermotolerance by interacting with HSP90.1 and affecting the accumulation of HsfA2-regulated sHSPs. Plant J Cell Mol Biol 59:387-399. https://doi.org/10.1111/j.1365-313x.2009.03878.x

Mittler R, Finka A, Goloubinoff P (2012) How do plants feel the heat? Trends Biochem Sci 37:118125. https://doi.org/10.1016/j.tibs.2011.11.007

Mohorianu I, Stocks MB, Wood J, Dalmay T, Moulton V (2013) CoLIde: a bioinformatics tool for CO-expression-based small RNA loci identification using high-throughput sequencing data. RNA Biol 10:1221-1230. https://doi.org/10.4161/rna.25538

Molnar A et al (2009) Highly specific gene silencing by artificial microRNAs in the unicellular alga Chlamydomonas reinhardtii. Plant J Cell Mol Biol 58:165-174. https://doi.org/10.1111/j.1365313X.2008.03767.x

Mourrain P et al (2000) Arabidopsis SGS2 and SGS3 genes are required for posttranscriptional gene silencing and natural virus resistance. Cell 101:533-542

Ohama N, Sato H, Shinozaki K, Yamaguchi-Shinozaki K (2017) Transcriptional regulatory network of plant heat stress response. Trends Plant Sci 22:53-65. https://doi.org/10.1016/j.tplants.2016. 08.015 
Pecinka A, Dinh HQ, Baubec T, Rosa M, Lettner N, Mittelsten Scheid O (2010) Epigenetic regulation of repetitive elements is attenuated by prolonged heat stress in Arabidopsis. Plant Cell 22:3118-3129. https://doi.org/10.1105/tpc.110.078493

Petroni K et al (2012) The promiscuous life of plant NUCLEAR FACTOR Y transcription factors. Plant Cell 24:4777-4792. https://doi.org/10.1105/tpc.112.105734

Poethig RS (2009) Small RNAs and developmental timing in plants. Curr Opin Genet Develop 19:374-378. https://doi.org/10.1016/j.gde.2009.06.001

Quint M, Delker C, Franklin KA, Wigge PA, Halliday KJ, van Zanten M (2016) Molecular and genetic control of plant thermomorphogenesis. Nat Plants 2:15190. https://doi.org/10.1038/ nplants.2015.190

Re DA, Lang PLM, Yones C, Arce AL, Stegmayer G, Milone D, Manavella PA (2019) Alternative use of miRNA-biogenesis co-factors in plants at low temperatures. Development 146. https://doi. org/10.1242/dev.172932

Rogers K, Chen X (2013) Biogenesis, turnover, and mode of action of plant microRNAs. Plant Cell 25:2383-2399. https://doi.org/10.1105/tpc.113.113159

Sailaja B, Voleti SR, Subrahmanyam D, Sarla N, Vishnuprasanth V, Bhadana VP, Mangrauthia SK (2014) Prediction and expression analysis of miRNAs associated with heat stress in Oryza sativa. Rice Sci 21:3-12

Scharf KD, Heider H, Hohfeld I, Lyck R, Schmidt E, Nover L (1998) The tomato Hsf system: HsfA2 needs interaction with HsfA1 for efficient nuclear import and may be localized in cytoplasmic heat stress granules. Mol Cell Biol 18:2240-2251

Scharf KD, Berberich T, Ebersberger I, Nover L (2012) The plant heat stress transcription factor (Hsf) family: structure, function and evolution. Biochimica et biophysica acta 1819:104-119. https://doi.org/10.1016/j.bbagrm.2011.10.002

Schommer C et al (2008) Control of jasmonate biosynthesis and senescence by miR319 targets. PLOS Biol 6:e230. https://doi.org/10.1371/journal.pbio.0060230

Schwab R, Ossowski S, Riester M, Warthmann N, Weigel D (2006) Highly specific gene silencing by artificial microRNAs in Arabidopsis. Plant Cell 18:1121-1133. https://doi.org/10.1105/tpc. 105.039834

Siriwardana CL, Gnesutta N, Kumimoto RW, Jones DS, Myers ZA, Mantovani R, Holt 3rd BF (2016) NUCLEAR FACTOR Y, Subunit A (NF-YA) Proteins positively regulate flowering and act through FLOWERING LOCUS T. PLOS Genet 12:e1006496. https://doi.org/10.1371/journal. pgen. 1006496

Spanudakis E, Jackson S (2014) The role of microRNAs in the control of flowering time. J Exp Bot 65:365-380. https://doi.org/10.1093/jxb/ert453

Srikanth A, Schmid M (2011) Regulation of flowering time: all roads lead to Rome. Cellular Mol Life Sci (CMLS) 68:2013-2037. https://doi.org/10.1007/s00018-011-0673-y

Stief A, Altmann S, Hoffmann K, Pant BD, Scheible WR, Baurle I (2014) Arabidopsis miR156 regulates tolerance to recurring environmental stress through spl transcription factors. Plant Cell 26:1792-1807. https://doi.org/10.1105/tpc.114.123851

Sun Z, Li M, Zhou Y, Guo T, Liu Y, Zhang H, Fang Y (2018) Coordinated regulation of Arabidopsis microRNA biogenesis and red light signaling through Dicer-like 1 and phytochrome-interacting factor 4. PLOS Genet 14:e1007247. https://doi.org/10.1371/journal.pgen.1007247

Sunkar R, Zhu JK (2004) Novel and stress-regulated microRNAs and other small RNAs from Arabidopsis. Plant Cell 16:2001-2019. https://doi.org/10.1105/tpc.104.022830

Sunkar R, Li YF, Jagadeeswaran G (2012) Functions of microRNAs in plant stress responses. Trends Plant Sci 17:196-203. https://doi.org/10.1016/j.tplants.2012.01.010

Szittya G et al (2003) Low temperature inhibits RNA silencing-mediated defence by the control of siRNA generation. EMBO J 22:633-640. https://doi.org/10.1093/emboj/cdg74

Vaucheret H (2006) Post-transcriptional small RNA pathways in plants: mechanisms and regulations. Genes Dev 20:759-771. https://doi.org/10.1101/gad.1410506 
Vaucheret H, Mallory AC, Bartel DP (2006) AGO1 homeostasis entails coexpression of MIR168 and AGO1 and preferential stabilization of miR168 by AGO1. Mol Cell 22:129-136. https://doi. org/10.1016/j.molcel.2006.03.011

Vidal EA, Araus V, Lu C, Parry G, Green PJ, Coruzzi GM, Gutierrez RA (2010) Nitrate-responsive miR393/AFB3 regulatory module controls root system architecture in Arabidopsis thaliana. Proc Nat Acad Sci USA 107:4477-4482. https://doi.org/10.1073/pnas.0909571107

Volkov RA, Panchuk II, Mullineaux PM, Schoffl F (2006) Heat stress-induced $\mathrm{H}_{2} \mathrm{O}_{2}$ is required for effective expression of heat shock genes in Arabidopsis. Plant Mol Biol 61:733-746. https:// doi.org/10.1007/s11103-006-0045-4

Wang JW (2014) Regulation of flowering time by the miR156-mediated age pathway. J Experim Botany 65:4723-4730. https://doi.org/10.1093/jxb/eru246

Wang JW, Wang LJ, Mao YB, Cai WJ, Xue HW, Chen XY (2005) Control of root cap formation by MicroRNA-targeted auxin response factors in Arabidopsis. Plant Cell 17:2204-2216. https:// doi.org/10.1105/tpc.105.033076

Wang JW, Czech B, Weigel D (2009) miR156-regulated SPL transcription factors define an endogenous flowering pathway in Arabidopsis thaliana. Cell 138:738-749. https://doi.org/10.1016/j.cell. 2009.06.014

Wang Y, Sun F, Cao H, Peng H, Ni Z, Sun Q, Yao Y (2012) TamiR159 directed wheat TaGAMYB cleavage and its involvement in anther development and heat response. PloS One 7:e48445. https://doi.org/10.1371/journal.pone.0048445

Wang QL, Chen JH, He NY, Guo FQ (2018) Metabolic reprogramming in chloroplasts under heat stress in plants. Int J Mol Sci 19. https://doi.org/10.3390/ijms19030849

Warthmann N, Chen H, Ossowski S, Weigel D, Herve P (2008) Highly specific gene silencing by artificial miRNAs in rice. PloS One 3:e1829. https://doi.org/10.1371/journal.pone.0001829

Wigge PA (2013) Ambient temperature signalling in plants. Curr Opin Plant Biol 16:661-666. https://doi.org/10.1016/j.pbi.2013.08.004

Xin M, Wang Y, Yao Y, Xie C, Peng H, Ni Z, Sun Q (2010) Diverse set of microRNAs are responsive to powdery mildew infection and heat stress in wheat (Triticum aestivum L.). BMC Plant Biol 10:123. https://doi.org/10.1186/1471-2229-10-123

Xin $\mathrm{M}$ et al (2011) Identification and characterization of wheat long non-protein coding RNAs responsive to powdery mildew infection and heat stress by using microarray analysis and SBS sequencing. BMC Plant Biol 11:61. https://doi.org/10.1186/1471-2229-11-61

Xing S, Salinas M, Garcia-Molina A, Hohmann S, Berndtgen R, Huijser P (2013) SPL8 and miR156targeted SPL genes redundantly regulate Arabidopsis gynoecium differential patterning. Plant J Cell Mol Biol 75:566-577. https://doi.org/10.1111/tpj.12221

Yamaguchi A, Wu MF, Yang L, Wu G, Poethig RS, Wagner D (2009) The microRNA-regulated SBP-Box transcription factor SPL3 is a direct upstream activator of LEAFY, FRUITFULL, and APETALA1. Develop Cell 17:268-278. https://doi.org/10.1016/j.devcel.2009.06.007

Yan K et al (2012) Stress-induced alternative splicing provides a mechanism for the regulation of microRNA processing in Arabidopsis thaliana. Mol Cell 48:521-531. https://doi.org/10.1016/j. molcel.2012.08.032

Yao Y, Sun Q (2012) Exploration of small non coding RNAs in wheat (Triticum aestivum L.). Plant Mol Biol 80:67-73. https://doi.org/10.1007/s11103-011-9835-4

Yoshida T et al (2011) Arabidopsis HsfA1 transcription factors function as the main positive regulators in heat shock-responsive gene expression. Mol Genetics Genomics (MGG) 286:321-332. https://doi.org/10.1007/s00438-011-0647-7

Yu N, Cai WJ, Wang S, Shan CM, Wang LJ, Chen XY (2010) Temporal control of trichome distribution by microRNA156-targeted SPL genes in Arabidopsis thaliana. Plant Cell 22:23222335. https://doi.org/10.1105/tpc.109.072579

$\mathrm{Yu} \mathrm{X}$ et al (2012) Identification of conserved and novel microRNAs that are responsive to heat stress in Brassica rapa. J Exp Bot 63:1025-1038. https://doi.org/10.1093/jxb/err337 
Zhong SH et al (2013) Warm temperatures induce transgenerational epigenetic release of RNA silencing by inhibiting siRNA biogenesis in Arabidopsis. Proc Natl Acad Sci USA 110:91719176. https://doi.org/10.1073/pnas.1219655110

Zhou R, Wang Q, Jiang F, Cao X, Sun M, Liu M, Wu Z (2016) Identification of miRNAs and their targets in wild tomato at moderately and acutely elevated temperatures by high-throughput sequencing and degradome analysis. Sci Rep 6:33777. https://doi.org/10.1038/srep33777

Zhu X, Huang C, Zhang L, Liu H, Yu J, Hu Z, Hua W (2017) Systematic analysis of Hsf family genes in the Brassica napus genome reveals novel responses to heat, drought and high $\mathrm{CO}_{2}$ stresses. Front Plant Sci 8:1174. https://doi.org/10.3389/fpls.2017.01174 